\title{
Elaboração e implementação de uma unidade didática baseada no Just-in-Time Teaching: um estudo sobre as percepções dos estudantes
}

Development and implementation of a teaching unit based on Just-in-Time Teaching: a study on students' perceptions

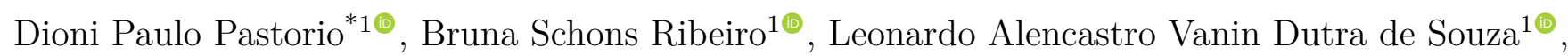

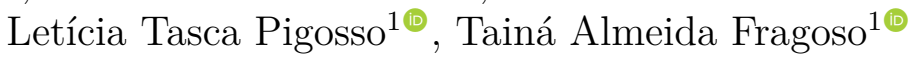 \\ ${ }^{1}$ Universidade Federal do Rio Grande do Sul, Instituto de Física, Porto Alegre, RS, Brasil.
}

Recebido em 17 de julho de 2020. Aceito em 25 de agosto de 2020 .

\begin{abstract}
Neste trabalho, desenvolvemos, implementamos e avaliamos uma sequência didática baseada na metodologia ativa Just-in-Time Teaching (JiTT - Ensino sob Medida). Nessa metodologia, os estudantes realizam tarefas antes da sala de aula e o professor, munido dos resultados das atividades, estrutura sua aula abordando, em especial, as dificuldades apresentadas. As tarefas, em geral, são de curta duração e envolvem, na maioria das vezes, questões conceituais e contextualizadas, aludindo o cotidiano do aluno de diferentes formas. Para isso, desenvolvemos uma revisão bibliográfica sobre o JiTT e discutimos a construção de dez tarefas. Após, analisamos a implementação em uma turma de nível superior do curso de Física. Os resultados encontrados, a partir da análise dos dados, apontam para uma boa aceitação por parte dos estudantes, fomentando o desenvolvimento de um hábito de estudos, em especial por proporcionar uma etapa de estudo pré aula. Além disso, o método potencializa a etapa presencial da aula, abordando temas específicos associados às dificuldades dos estudantes. Apesar desses aspectos positivos, a carga excessiva de trabalho foi mencionada por um estudante. Por fim, destacamos a importância do desenvolvimento, da implementação e da avaliação de propostas, trazendo à tona discussões que envolvam a mudança da percepção do aluno no processo de ensino e aprendizagem.
\end{abstract}

Palavras-chave: Metodologias Ativas, Ensino de Física, Just-in-Time Teaching, Rotina de Estudo, Percepção do Aluno.

In this work, we develop, implement and evaluate a didactic sequence based on the Just-in-Time Teaching active methodology. In this methodology, students perform tasks before the classroom and the teacher structures his class based on the results of activities, especially addressing the difficulties presented. The tasks, in general, are of short duration and involve, in most cases, conceptual and contextualized questions, approaching the student's daily life in different ways. Thereunto, we developed a bibliographic review on JiTT and discussed the construction of ten tasks. Afterwards, we analyzed the implementation in a Physics course undergraduate class. The results found, from the data analysis, point to a good acceptance on the part of the students, promoting the development of a study habit, especially for providing a pre-class study stage. In addition, it potentializes the classroom stage of the class, addressing specific topics. Despite these positive aspects, the excessive workload was mentioned by one student. Finally, we highlight the importance of developing, implementing and evaluating proposals, bringing up discussions that involve changing the student's perception in the teaching and learning process.

Keywords: Active Methodologies, Physics Teaching, Just-in-Time Teaching, Study Habits, Student Perception.

\section{Introdução}

O Ensino de Física tem se mostrado defasado ao longo do tempo, sendo visto como um amontoado de equações, as quais os estudantes devem memorizar para que possam aplicar em exercícios que fazem referência a situações já idealizadas ou prontas, tornando o conhecimento adquirido pelos estudantes limitado a situações específicas e mecanizadas [1]. Além disso, tanto na Educação Básica quanto no Ensino Superior, os conteúdos de Física são

*Endereço de correspondência: dionipastorio@hotmail.com apresentados de maneira descontextualizada, carecendo de maiores discussões e reflexões, causando dessa forma, pouco interesse e desmotivação por parte dos estudantes $[2,3]$.

Com base nesta visão, no intuito de superar esses obstáculos acima destacados, as metodologias ativas de ensino são uma alternativa para a abordagem do Ensino de Física. Para Berbel, as metodologias ativas são "processos interativos de conhecimento, análise, estudo, pesquisa e decisões individuais ou coletivas com finalidade de encontrar soluções para um problema" [4, p. 29], de modo que 
o professor esteja presente como um orientador do tema a ser pesquisado. Berbel [4] defende também a utilização de desafios, já que estes seriam instrumentos de inspiração na hora de construir o conhecimento. Algumas das metodologias ativas mais conhecidas na área de Ensino de Física são: (i) a aprendizagem baseada em problemas [5], (ii) aprendizagem baseada em projetos [6] - que não são a mesma metodologia [7], (iii) instrução pelos colegas [8] e o (iv) Just-in-Time Teaching (JiTT, ou Ensino sob Medida em português) [9]. Não tencionamos aqui abordar e discutir todas essas metodologias.

Optamos pela utilização do JiTT para o desenvolvimento da sequência didática explorada neste artigo por entendermos que é uma metodologia de ensino que (i) coloca o aluno em um papel ativo de aprendizagem; (ii) facilita a contextualização dos conteúdos; (iii) permite ao aluno uma preparação prévia para a aula presencial; (iv) proporciona ao professor um melhor entendimento das dificuldades dos seus alunos, permitindo a otimização das aulas; (v) favorece a adoção de uma rotina de estudos constante pelos estudantes. Como objetivo da implementação, buscamos fomentar os itens citados acima. Já como objetivo da pesquisa, procuramos entender se esses tópicos foram alcançados, na visão dos estudantes, e também que pontos da metodologia em si e da execução da sequência didática podem ser aperfeiçoados para adoções em futuras turmas/disciplinas. Nesse sentido, a pesquisa busca responder a seguinte pergunta: a implementação da metodologia de ensino-aprendizagem Just-in-Time Teaching em uma disciplina introdutória de Física contribuiu para a preparação dos alunos no momento pré-classe, para a otimização do tempo de aula e para o estabelecimento de uma rotina de estudos?

\section{Just-in-Time Teaching}

Os estudos de metodologias ativas comumente apresentam o Just-in-Time Teaching (JiTT) de Gregory M. Novak et al. [9] como uma alternativa ao ensino tradicional, atentando para sua aplicação e fundamentos teóricos. Este método pode ser trabalhado em três momentos principais: a aplicação das tarefas de leitura (TL), as discussões em aula sobre as TL e as atividades em grupo que envolvem os conceitos trabalhados [10]. As TL são conhecidas originalmente como "Warm Up Exercises" (exercícios de aquecimento) e são passadas para os estudantes antes da aula. Nelas, o professor solicita que os alunos estudem um material, o qual pode ser um vídeo, um artigo ou semelhantes, e em seguida é solicitado que o estudante responda a algumas questões conceituais sobre o que acabou de ler e que devem ser enviadas ao professor com antecedência mínima para a devida preparação da aula. Esta etapa tem como objetivos promover o pensamento crítico sobre o material estudado, introduzir o que será trabalhado, conduzir os alunos a desenvolverem argumentos sobre o tema e ainda serve de guia para o professor preparar sua aula. É sugerido, também, que as tarefas de leitura sejam tarefas curtas, para que o aluno não se sinta desmotivado na hora de realizá-las.

O segundo momento é a discussão em sala de aula sobre a TL. Com as respostas recebidas, o professor pode analisar os pontos de maior dificuldade, preparar o momento de exposição e selecionar atividades que poderão suprir as necessidades específicas dos estudantes. Em aula, o professor pode mostrar as questões novamente e apresentar algumas respostas dos alunos (em anonimato) para que sirvam como norteadoras de discussão, de forma que possam apontar os erros e mostrar caminhos alternativos para o desenvolvimento. É fundamental, nessa etapa, que o professor analise as questões com antecedência para promover uma melhor avaliação dos resultados apresentados.

Na terceira etapa do método é realizado o desenvolvimento e a aplicação de atividades sobre os conceitos trabalhados. Como a aula foi preparada com foco nas dificuldades dos alunos, é esperado que o tempo de aula seja otimizado, ou seja, com breve exposição do tema por parte do professor e foco nas discussões e realização de atividades de fixação.

Além de compreendermos bem as bases do JiTT, também realizamos uma breve revisão de estudos anteriores sobre esta metodologia, a fim de enriquecer a estrutura didática construída e implementada. Esta revisão é discutida detalhadamente na subseção seguinte.

\subsection{Revisão da literatura}

Para entender como o JiTT vem sendo estudado e aplicado, e a partir disso balizar as ações aqui propostas e implementadas, fizemos uma revisão da literatura dentre as principais revistas de Ensino de Física e de Educação em Ciências. A coleta dos dados se deu a partir da lista de classificações qualis Capes ${ }^{1}$ que organiza as revistas em níveis de acordo com sua qualidade. Buscamos por revistas na área de Ensino de Física e Educação em Ciências de níveis A1, A2 e B1 ${ }^{2}$. No total, foram encontradas 63 revistas cujos título e foco estavam associados aos temas já destacados. Nos motores de busca de cada revista foram utilizadas as seguintes palavras-chave para o desenvolvimento da pesquisa: métodos ativos; ensino sob medida; Just-in-Time Teaching. Quatro periódicos, três internacionais e um nacional, a partir de suas datas de publicações até 2019, apresentaram resultados para as pesquisas e foram encontrados sete artigos que tratavam dos temas pesquisados. Desse modo, a partir da leitura dos artigos, buscamos entender como foram feitas as aplicações ou como o JiTT era trabalhado. Destes, apenas quatro realizaram aplicações enquanto os outros três tratavam do método de forma teórica. Segue abaixo a Tabela 1 com os artigos encontrados.

Com estes artigos em mãos, passamos a estudar os trabalhos com análise de prática desenvolvida, ou seja,

$\overline{1}$ https://sucupira.capes.gov.br/sucupira/public/ consultas/coleta/veiculoPublicacaoQualis/ listaConsultaGeralPeriodicos.jsf

2 Classiticações referentes ao quadriênio 2016-2019. 
Tabela 1: Artigos encontrados em cada periódico com seus autores, título e nível da revista.

\begin{tabular}{|c|c|c|c|}
\hline $\begin{array}{l}\text { Revista } \\
\text { (Nível Qualis Capes) }\end{array}$ & Referência & Título & Autores \\
\hline $\begin{array}{l}\text { Journal of Science Edu- } \\
\text { cation and Technology } \\
\text { (A1) }\end{array}$ & {$[11]$} & $\begin{array}{l}\text { Just-in-Time Teaching Exercises to Engage Students in an } \\
\text { Introductory-Level Dinosaur Course. }\end{array}$ & $\begin{array}{l}\text { A.L. Guertin, S.E. Zappe } \\
\text { e H. Kim. }\end{array}$ \\
\hline \multirow[t]{3}{*}{$\begin{array}{l}\text { The Physics Teacher } \\
\text { (A1) }\end{array}$} & {$[12]$} & Just-in-Time to Flip Your Classroom. & $\begin{array}{l}\text { N. Lasry, M. Dugdale e } \\
\text { E. Charles. }\end{array}$ \\
\hline & {$[13]$} & $\begin{array}{l}\text { Electrostatic Activities, and a website for implementing Peer } \\
\text { Instruction and Just-in-Time Teaching: The Interactive } \\
\text { Learning Toolkit. }\end{array}$ & D. MacIsaac \\
\hline & {$[14]$} & $\begin{array}{l}\text { The Combination of Just-in-Time Teaching and Wikispaces } \\
\text { in Physics Classrooms. }\end{array}$ & H. E. Mohottala \\
\hline \multirow[t]{2}{*}{$\begin{array}{l}\text { Caderno Brasileiro de } \\
\text { Ensino de Física (A2) }\end{array}$} & {$[10]$} & $\begin{array}{l}\text { Instruções Pelos Colegas e Ensino sob Medida: Uma Proposta } \\
\text { para o Engajamento dos Alunos no Processo de Ensino- } \\
\text { Aprendizagem de Física. }\end{array}$ & I. S. Araujo e E. Mazur \\
\hline & {$[15]$} & $\begin{array}{l}\text { Relato de experiência com os métodos Ensino sob Medida } \\
\text { (Just-in-Time Teaching) e Instrução pelos Colegas (Peer } \\
\text { Instruction) para o Ensino de Tópicos de Eletromagnetismo } \\
\text { no nivel médio. }\end{array}$ & $\begin{array}{l}\text { V. Oliveira, E. A. Veit } \\
\text { I. S. Araujo }\end{array}$ \\
\hline $\begin{array}{l}\text { Revista de Enseñanza de } \\
\text { la Física (B1) }\end{array}$ & {$[16]$} & $\begin{array}{l}\text { Aula Invertida (flipped classroom): innovando las clases de } \\
\text { física. }\end{array}$ & $\begin{array}{l}\text { T. Espinosa, I. S. Araujo } \\
\text { e E. A. Veit }\end{array}$ \\
\hline
\end{tabular}

os artigos [11], [12], [14] e [15], para que pudéssemos tomar como base em nossa proposta de implementação. A primeira aplicação que analisamos foi a realizada por Guertin, Zappe e Kim [11] em uma disciplina sobre dinossauros em um curso introdutório de graduação. Os principais objetivos dos autores eram que os alunos desenvolvessem ferramentas intelectuais e aprendessem estratégias necessárias para adquirir conhecimento. Após algumas análises de diferentes métodos optou-se pelo uso do JiTT, já que este seria o método mais otimizado no quesito tempo para a sala de aula. A aplicação se deu uma vez por semana; os estudantes deveriam acessar a plataforma "DinoBytes", uma plataforma on-line, e responder questões que deveriam ser enviadas até duas horas antes da aula para que os monitores da disciplina pudessem organizar o material expositivo. Na plataforma era possível ter acesso a um material que seria estudado e, em seguida, eram respondidas questões de demonstração de conhecimentos, outra de interpretação e, por último, uma de avaliação do material.

Já Mohottala [14] utiliza o JiTT juntamente com uma plataforma de hospedagem de wiki. Nesta aplicação, o professor criou uma página wiki em que disponibilizaria as tarefas de leitura, ou seja, o material para estudo e as questões para os alunos. Em seguida, solicitou que os estudantes criassem suas próprias páginas para que pudessem publicar suas respostas e para que os colegas pudessem interagir, no formato de sugestões (este passo não era obrigatório). As questões dadas pelo professor eram principalmente do tipo puzzle, ou seja, era possível realizar uma série de cálculos para chegar em um resultado numérico, entretanto, foi solicitado pelo professor que os estudantes não fizessem tais cálculos, e sim que criassem um passo a passo que poderia ser seguido para chegar na resposta final. Em certo momento, o professor ainda disponibilizou um roteiro sobre como as questões deveriam ser respondidas em seis etapas. O autor cita que há um diferencial na sua aplicação já que os problemas propostos seriam dados durante o estudo de um certo tema, e não antes como proposto por Novak et al. [9].

No trabalho de Lasry, Dugdale e Charles [12] havia o objetivo de aplicar o método Instrução pelos Colegas (Peer Instruction) em uma disciplina cujo tema seria eletricidade e magnetismo. Entretanto, devido à escassez de tempo, nem todos os tópicos poderiam ser abordados em aula. Dessa forma, optou-se pelo uso do JiTT para preencher esta lacuna. O chamado "Flip-JiTT", desenvolvido por Lasry, passa por algumas fases intermediárias ainda, descritas em seis momentos: 1) "O que você sabe?"; 2) adquirir informação; 3) questões de aquecimento; 4) "o que você sabe agora?" 33 5) reflexão sobre os aprendizados; 6) descrição das dificuldades. Os resultados encontrados foram aparentemente promissores, com um índice de participação de $83 \%$ nas tarefas pré-classe.

Por fim, analisamos o trabalho de Oliveira, Veit e Araujo [15], que também realizaram a aplicação do JiTT com base nos escritos de Novak et al. [9]. O método foi aplicado em uma turma do ensino técnico, utilizando tópicos de eletromagnetismo. Para esta aplicação, houve a preocupação com os conhecimentos prévios dos estudantes e por isso os autores aplicaram testes iniciais e conceituais baseados em questões de vestibular sobre o tema a ser trabalhado. Como resultado, os autores afirmam ter dobrado o aproveitamento da turma e uma boa aceitação do método.

Baseado nos artigos aqui mostrados, pode-se observar pontos influentes nas aplicações e semelhanças entre os trabalhos desenvolvidos, por isso optou-se por usar como base principal o trabalho de Araujo e Mazur [10] para desenvolver, implementar e avaliar uma sequência didática para a disciplina de Física Geral I de um curso de Bacharelado e Licenciatura em Física com a utilização do JiTT. A escolha deste artigo para a base do desenvolvimento deste trabalho está na forma como é apresentado

\footnotetext{
3 Tradução pelos autores.
} 
o método e principalmente em como são desenvolvidas as TL. Nas seções seguintes mostraremos a concepção de pesquisa adotada, além de como foram desenvolvidas as tarefas de leitura e como se deu o aproveitamento dos alunos.

\section{Metodologia e Estruturação da Pesquisa}

\subsection{Locus de pesquisa}

A pesquisa descrita no presente artigo foi realizada em uma turma da disciplina de Física Geral I na Universidade Federal do Rio Grande do Sul. Essa turma em específico era direcionada para alunos dos cursos de Licenciatura em Física, mas isso não impedia a matrícula de alunos de outros cursos, como de fato tivemos alguns estudantes de Bacharelado em Física e um estudante do curso de Geologia.

A disciplina de Física Geral I está no currículo da Licenciatura em Física no segundo semestre de curso, enquanto para o Bacharelado em Física e para a Geologia, está no primeiro semestre. É uma disciplina que trata sobre conteúdos de física básica, mais especificamente mecânica.

Essa turma contava, inicialmente, com 31 alunos matriculados. Entretanto, desde o início do semestre letivo, um número um pouco menor de alunos frequentava de fato as aulas, aproximadamente 25. Essa média decresceu um pouco mais conforme o semestre foi avançando (prática comum associada a evasão nos cursos de Física, posteriormente destacadas neste trabalho), o que nos resultou em um número em torno de 20 estudantes ativamente participando da segunda metade da disciplina. Esse foi o total de alunos, inclusive, que realizou a última avaliação, o que nos dá uma ideia de quantos estudantes, efetivamente, acompanharam a disciplina até o final.

\subsection{Concepção de pesquisa}

A concepção de pesquisa utilizada é a Investigação-Ação Educacional (IAE), que consiste em uma investigação sistemática que nos possibilita evidenciar problemas práticos existentes no processo de ensino-aprendizagem, de modo a buscar possíveis soluções para esses problemas [17]. Essa é a principal justificativa para a escolha da IAE, uma vez que, através de nossa pesquisa, também buscamos atuar em uma problemática concreta e específica, que diz respeito ao desenvolvimento de um ritmo de estudos a partir de uma sequência didática baseada em metodologias ativas, nesse caso específico, o JiTT.

\subsection{Estruturação dos momentos da pesquisa}

$\mathrm{Na}$ IAE, o pesquisador encontra-se inserido no contexto da pesquisa, com o foco na melhoria daquele cenário. Ainda, segundo Carr e Kemmis [18], a investigação se configura a partir da integração de alguns momentos que serão mostrados na Tabela 2, seguidos pela descrição das formas como esses itens foram inseridos na implementação do JiTT.

Cada um desses momentos implica um olhar retrospectivo e uma intenção prospectiva, formando uma espiral cíclica que produz um movimento contínuo de açãoreflexão-ação [18].

\subsection{Instrumentos de coleta de dados}

Durante o desenvolvimento dos momentos da IAE, utilizamos os seguintes instrumentos para a coleta dos dados:

- Questionário inicial: esse questionário tem como objetivo investigar o perfil do estudante participante da disciplina. Essa informação pode ser fundamental, na medida que nos possibilita planejar mais adequadamente a construção e o andamento das atividades.

- Questionário final: nesse questionário, objetivamos identificar quais foram as opiniões e ideias que os alunos expressaram a respeito da realização de todo o processo apresentado na disciplina.

Tabela 2: Momentos de pesquisa e a inserção no contexto da implementação.

\begin{tabular}{|c|c|c|}
\hline Item & Explanação & Inserção no JiTT \\
\hline Planejamento & $\begin{array}{l}\text { Antecede a ação, organizando-a com } \\
\text { o objetivo de auxiliar na atuação do } \\
\text { professor em uma futura situação edu- } \\
\text { cativa. }\end{array}$ & $\begin{array}{l}\text { O planejamento foi realizado na criação das TL, quando da escolha do } \\
\text { tema, busca de recursos e criação de questões que proporcionassem o } \\
\text { raciocínio do aluno e ajudassem o professor na identificação de dúvidas } \\
\text { e dificuldades. }\end{array}$ \\
\hline Ação & Implementação do planejamento. & $\begin{array}{l}\text { A disponibilização das TL na plataforma utilizada e o retorno posterior } \\
\text { (avaliação das tarefas) dado aos alunos quanto suas respostas. }\end{array}$ \\
\hline Observação & $\begin{array}{l}\text { Acompanhamento e registro dos efeitos } \\
\text { da ação. }\end{array}$ & $\begin{array}{l}\text { Para cada TL realizada, um documento era criado com observações } \\
\text { quanto às respostas dos alunos, às dificuldades percebidas e às dúvidas } \\
\text { que surgiam, assim como indicações de alguns problemas percebidos na } \\
\text { compreensão dos temas e conteúdos. }\end{array}$ \\
\hline Reflexão & $\begin{array}{l}\text { Movimento retrospectivo no qual as- } \\
\text { pectos (positivos e negativos) da ação } \\
\text { são recordados, consistindo ainda em } \\
\text { um ponto de partida para um repla- } \\
\text { nejamento da ação, reiniciando o pro- } \\
\text { cesso. }\end{array}$ & $\begin{array}{l}\text { O professor, munido das observações, preparava a aula com base nos } \\
\text { comentários e respostas dos alunos às TL, enfatizando os assuntos em } \\
\text { que os alunos mostraram dificuldades e sanando as dúvidas que surgiram, } \\
\text { ao mesmo tempo abordando o conteúdo de forma mais aprofundada, } \\
\text { mas que era previamente conhecida pelo alunos por conta da TL. Além } \\
\text { disso, cada avaliação de TL possibilitava que a próxima fosse construída, } \\
\text { levando em consideração as dificuldades apresentadas. }\end{array}$ \\
\hline
\end{tabular}


- Respostas aos testes apresentados: diz respeito à análise de como os estudantes desenvolveram as atividades propostas. Consiste na avaliação do material impresso apresentado, bem como na percepção de como o aluno entendeu o processo.

Mais à frente, nas próximas seções, discutiremos mais profundamente sobre os instrumentos de coleta de dados aqui utilizados, assim como os dados obtidos. Passamos, agora, à descrição das atividades desenvolvidas.

\section{Descrição do Método da Disciplina}

Nesta seção será descrito como aplicamos o método em uma disciplina inicial de Física para graduação, passando pelas etapas do JiTT e mostrando principalmente, como cada TL foi aplicada e o que foi trabalhado nela. Ainda serão trazidos resultados sobre a opinião dos alunos em cada uma das tarefas e como foi feita a avaliação.

Nessa disciplina, utilizamos o JiTT de maneira conectada ao desenvolvimento do curso. No que tange ao JiTT, o meio de aplicação foi a plataforma Moodle um ambiente virtual em que os alunos têm acesso a materiais, recursos e informações disponibilizados pelo professor e também é intermédio de contato entre alunos, professor e monitores, aumentando a interação a longa distância e facilitando a comunicação, além de possibilitar que dúvidas e questionamentos possam ser discutidos rapidamente.

A construção das tarefas de leitura foi realizada buscando a contextualização [19-21], ou seja, considerando a importância do aluno identificar os fenômenos físicos no seu cotidiano e em diferentes contextos; mesmo sem conhecer profundamente o conceito envolvido, o estudante pode observar que há uma relação entre o que ele vai aprender e as situações que enxerga ao seu redor. Os trechos introdutórios das TL têm o intuito de instigar o aluno a ler o texto da tarefa ou assistir aos vídeos e incentivar a análise dos fenômenos envolvidos para adiantar o conceito que será abordado. O material no qual se baseiam as questões (textos ou vídeos) mostram alguma situação do cotidiano ou próxima à realidade do aluno e que envolva os fenômenos que serão estudados em aula.

Pelo fato de as TL explorarem a contextualização, buscamos intervir no modelo de questões sugeridas por Novak et al. [9] da mesma forma que Araujo e Mazur [10] o fizeram, apresentando questões abertas e subjetivas, fazendo com que os estudantes desenvolvam suas respostas através de uma breve dissertação sobre como um problema poderia ser desenvolvido ou resolvido. Além disso, seguimos a recomendação de Araujo e Mazur [10] de manter a última questão da TL como um espaço aberto para os estudantes apontarem suas dificuldades ao longo da tarefa.

Os temas das tarefas implementadas são baseados nos conceitos que são estudados ao longo da disciplina de Física Geral I e a ordem destas, assim como os assuntos que abordam, segue uma progressão baseada nos capítulos da bibliografia essencial da disciplina, segundo o

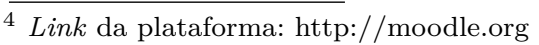

plano de ensind 5 Abaixo, na Tabela 3, pode-se visualizar os tópicos abordados e os recursos utilizados (as tarefas podem ser consultadas na íntegra no link compartilhado em nota ${ }^{6}$.

No total, dez tarefas de leitura foram aplicadas, com o objetivo de proporcionar uma avaliação conceitual e qualitativa dos conhecimentos iniciais dos alunos. As tarefas em questão eram postadas na plataforma do Moodle com um formato de questionário (ver Figura 1). As perguntas deveriam ser respondidas no próprio ambiente virtual e eram, assim que terminadas e enviadas pelo aluno, contabilizadas como tentativas e ficavam disponíveis para a avaliação. Um limite de tempo era definido para a realização das tarefas assim que o aluno abrisse o questionário, como uma forma de verificar quanto tempo os alunos utilizavam para realizá-las e, também, com o intuito de mostrar que elas poderiam ser feitas em pouco temp ${ }^{7}$. Em geral, tarefas mais curtas (com menos questões) tinham 30 minutos de tempo limite e as tarefas mais longas (com mais questões) tinham duração máxima de cerca de uma hora. Apesar da margem de tempo maior, as tarefas eram simples em conteúdo e estrutura e o tempo imaginado para a resolução delas não era superior a 15 minutos.

As tarefas de leitura, como citado anteriormente, eram aplicadas sempre antes da aula em que o professor iria desenvolver o assunto abordado, em geral com antecedência de uma semana. Dessa forma o aluno teria uma introdução ao conteúdo e, além disso, poderia avaliar seus

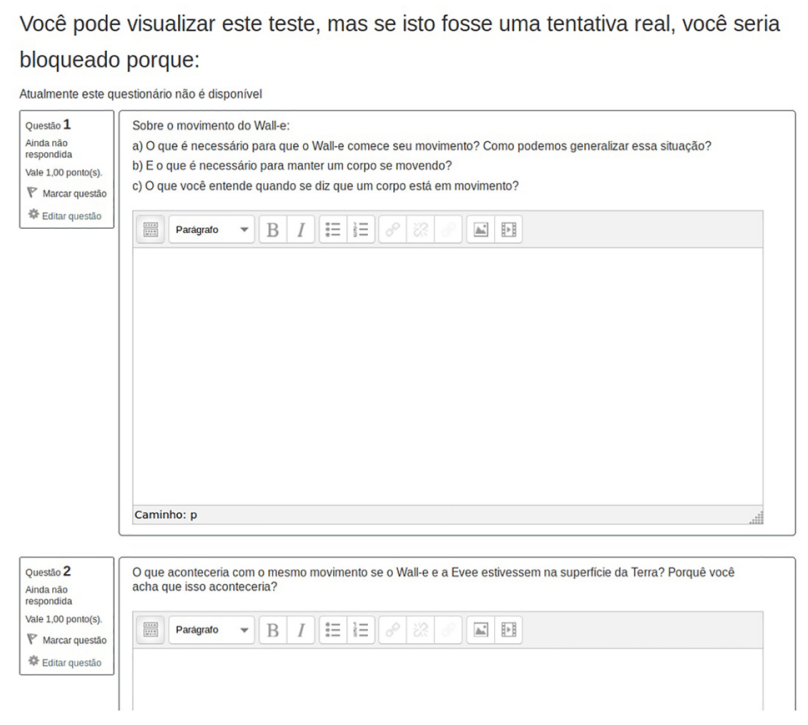

Figura 1: Exemplo de Tarefa no Moodle.

\footnotetext{
5 Halliday, D.; Resnick, R.; Walker, J. (2008). Fundamentos de Física. Rio de Janeiro: LTC.

6 Link para tarefas na íntegra: https://docs.google.com/document/d/1g-yZcZ90bKaNu6D7LKkYVAcLHEXG5T ring

7 De acordo com o que propõe o JiTT, as tarefas de leitura devem possuir uma estrutura que permita que elas sejam realizadas rapidamente, evitando que consuma muito tempo fora da sala de aula. Para isso, as questões propostas são conceituais e simples.
} 
Tabela 3: Tarefas de Leitura: progressão, temas e recursos utilizados.

\begin{tabular}{|c|c|c|}
\hline $\begin{array}{l}\text { Número } \\
\text { da tarefa }\end{array}$ & Tema & Recurso utilizado \\
\hline 1 & $\begin{array}{ll}\text { Medição e } \\
\text { Grandezas }\end{array}$ & $\begin{array}{l}\text { Vídeo: A revolução das Medidas (mostra as transformações nas formas de medição e a história de } \\
\text { algumas das principais unidades de medida). }\end{array}$ \\
\hline 2 & $\begin{array}{l}\text { Movimento } \\
\text { Retilíneo }\end{array}$ & $\begin{array}{l}\text { Vídeos: } 100 \text { metros rasos e } 100 \text { metros rasos com barreiras (o aluno analisa as gravações de atletas } \\
\text { nas duas modalidades de corrida). }\end{array}$ \\
\hline 3 & Vetores & $\begin{array}{l}\text { Atividade Computacional: Vetores (uma simulação em que o aluno pode manipular vetores e analisar } \\
\text { as definições destes). }\end{array}$ \\
\hline 4 & $\begin{array}{l}\text { Movimento } \\
\text { Bidimensio- } \\
\text { nal }\end{array}$ & $\begin{array}{l}\text { Vídeo: Futebol (gravação de uma cobrança de falta, em um jogo de futebol, para análise do movimento } \\
\text { da bola). }\end{array}$ \\
\hline 5 & Força & $\begin{array}{l}\text { Vídeo: Wall-E (um trecho do filme de animação para análise do movimento do robô no espaço) - } \\
\text { Artigo Extra: Dos "principia"da mecânica aos "principia"de Newton. }\end{array}$ \\
\hline 6 & $\begin{array}{l}\text { Força } \\
\text { Atrito }\end{array}$ & $\begin{array}{l}\text { Vídeo: Patinação no gelo (uma gravação da patinadora artística Isadora Williams em uma de suas } \\
\text { apresentações, para a análise das forças envolvidas em seus movimentos). }\end{array}$ \\
\hline 7 & $\begin{array}{l}\text { Trabalho } \\
\text { Energia }\end{array}$ & $\begin{array}{l}\text { Vídeo: Crossfit (uma gravação de pessoas praticando crossfit, o aluno analisa as questões envolvendo } \\
\text { energia e trabalho nesse contexto de exercícios físico). }\end{array}$ \\
\hline 8 & Energia & $\begin{array}{l}\text { Texto: Energia e História (apresenta uma contextualização histórica das descobertas em relação à } \\
\text { energia, o uso e a importância desta, retirado de um caderno do Prêmio Jovem Cientista). }\end{array}$ \\
\hline 9 & Colisões & $\begin{array}{l}\text { Simulação computacional: Laboratório de colisões (uma simulação em que o aluno pode manipular } \\
\text { diferentes colisões e analisar os fenômenos envolvidos). Vídeo: Jogo de bilhar (uma exemplificação } \\
\text { cotidiana de colisões). }\end{array}$ \\
\hline 10 & Torque & $\begin{array}{l}\text { Artigo: Como trocar o pneu de um carro (link para acesso a um artigo de blog que explica os passos } \\
\text { para a troca de um pneu e fala sobre as ferramentas ideais no processo, é possível visualizar questões } \\
\text { que envolvem torque em uma situação corriqueira). }\end{array}$ \\
\hline
\end{tabular}

conhecimentos sobre o assunto, observar os fenômenos em diferentes contextos e buscar por mais informações, experimentando, assim, um método diferenciado de estudo.

Nesse momento, vamos destacar a estrutura comum das TL, que iniciavam com os trechos introdutórios já citados, a disponibilização de um texto ou vídeo referente a algum assunto que envolvia a análise de fenômenos e conceitos da Física, além das questões propostas. Ademais, ao final de cada TL havia um espaço para o aluno descrever sua opinião a respeito da atividade, os aspectos positivos e negativos e as dificuldades encontradas [10]. Abaixo, a título de exemplo e demonstração, destacamos o texto introdutório da Tarefa de Leitura 5 (Força) e, na Tabela 4, as questões que foram propostas:

"Ao chutarmos uma parede machucamos nossos pés, assim como quando uma bola bate com uma certa velocidade numa parede ela retorna. Em nosso dia-a-dia estamos cercados de fenômenos que parecem distintos mas que, na verdade, estão todos relacionados pela mesma grandeza. Newton foi o primeiro a nomear essa grandeza, porém muitos outros já haviam relacionado esses fenômenos entre si.

O fator mais importante que apareceu junto com esses estudiosos foi a forma de enxergar o mundo. O céu deixou de ser um lugar perfeito, feito de um material que não havia na Terra (éter), onde as leis que valiam na Terra não eram mais válidas. O espaço passou a ser um lugar imaginável, com fenômenos que acontecem da mesma forma como vemos no planeta Terra. O vídeo a seguir é um recorte da animação produzida pela Pixar "Wall-e" que mostra a forma como hoje em dia as leis da Fúsica são retratadas no espaço.
É claro que essa ideia levou anos para ser legitimada na comunidade cientifica e até hoje continuamos reproduzindo algumas dessas ideias. Caso queira saber mais sobre a legitimação dessa grandeza e da forma como a conhecemos hoje você pode ler o artigo a seguir."

A avaliação das tarefas de leitura era feita por participação e não possuía o intuito de pontuar o aluno por

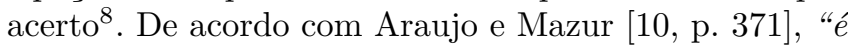
aconselhável que as questões sejam avaliadas com base no esforço demonstrado para o desenvolvimento de uma argumentação coerente e não em seu grau de correção."

A avaliação era feita em conjunto, entre o docente e os monitores da disciplina, que corrigiam individualmente cada questão, apontando os erros dos alunos de forma a introduzir conceitos básicos que seriam vistos em aula ou mesmo orientando sobre possíveis observações que poderiam ser feitas, muitas vezes estimulando o aluno para a aula futura e repassando as maiores dificuldades para o professor. Além disso, a análise das respostas poderia incentivar o aluno a pesquisar sobre o assunto, a desenvolver melhor sua argumentação ou mesmo motivá-lo a continuar realizando as tarefas com o mesmo empenho. Vale ressaltar que o retorno dessa avaliação para os alunos era realizado de forma rápida, um fator muito importante, pois é com esse retorno que o aluno pode analisar suas dúvidas e curiosidades acerca do assunto e levar essas questões para serem discutidas em aula, além de perceber que sua participação era valorada pelo professor [10].

\footnotetext{
8 Foi atribuído 0,5 ponto na média final da disciplina para quem realizou todas as tarefas de leitura.
} 
Tabela 4: Questões propostas na Tarefa de Leitura 5.

\begin{tabular}{|c|c|}
\hline $\begin{array}{l}\text { Número da } \\
\text { questão }\end{array}$ & 10 \\
\hline 1 & $\begin{array}{l}\text { Sobre o movimento do Wall-e: } \\
\text { a) O que é necessário para que o Wall-e comece seu movimento? Como podemos generalizar essa situação? } \\
\text { b) E o que é necessário para manter um corpo se movendo? } \\
\text { c) O que você entende quando se diz que um corpo está em movimento? }\end{array}$ \\
\hline 2 & $\begin{array}{l}\text { O que aconteceria com o mesmo movimento se o Wall-e e a Evee estivessem na superfície da Terra? Por que } \\
\text { você acha que isso aconteceria? }\end{array}$ \\
\hline 3 & $\begin{array}{l}\text { Como você explica o fato de que quando um ônibus em movimento é freado os passageiros são "arremessados" } \\
\text { para a frente? Como você relaciona esse fator ao movimento do Wall-e? }\end{array}$ \\
\hline 4 & $\begin{array}{l}\text { Descreva qual(is) ponto(s) você teve mais dificuldade na tarefa e indique também os pontos que mais chamaram } \\
\text { sua atenção. }\end{array}$ \\
\hline
\end{tabular}

\section{Contexto Baseado no Questionário Inicial}

Com o objetivo de traçar um perfil da turma em que esse trabalho foi realizado e também obter informações relevantes para a aplicação da metodologia ao longo da disciplina, no início do semestre, desenvolvemos e disponibilizamos um questionário não obrigatório e não avaliativo, denominado questionário inicial, o qual continha 24 perguntas. As questões envolviam temas como uso do celular, computador, tecnologias e internet como ferramentas didáticas em sala de aula 9 Ao todo, 16 alunos submeteram suas respostas ao questionário, de um total de 31 alunos matriculados na turma. Vale ressaltar que o número de alunos que efetivamente participavam das aulas era menor, cerca de 25 alunos no início do semestre e, portanto, aqueles que não responderam o questionário representam uma parcela pequena dos estudantes que acompanhavam a disciplina e não podemos e tampouco tencionamos afirmar os motivos que os levaram a não respondê-lo. Munidos dessas informações, construímos as atividades em consonância com as necessidades, anseios e dificuldades específicas de nossos estudantes. Abaixo, destacamos a análise do mesmo, indicando apenas as questões mais relevantes.

Para o desenvolvimento da presente pesquisa, por envolver fortemente o uso de Tecnologias de Informação e Comunicação (TIC), buscamos conhecer a realidade dos estudantes quanto ao uso de dispositivos móveis e computadores, assim como o acesso à internet. Sobre o uso de celular, destacamos que todos possuíam e tinham acesso à internet. Para a maioria deles (61\%), o acesso à internet era limitado, entretanto, havia a possibilidade de utilizar a rede Wi-Fi do local, possibilitando a acesso por parte de todos. Essas informações foram importantes para o desenvolvimento das atividades realizadas com a turma ao longo do semestre, visto que as tarefas de leitura aplicadas eram disponibilizadas via plataforma virtual (Moodle) e necessitavam de acesso à internet.

\footnotetext{
9 Essas ferramentas estão presentes em toda a aplicação. Logo, seria fundamental compreender se os estudantes faziam uso das mesmas no seu cotidiano, afinal, o intuito era propiciar um ambiente favorável ao desenvolvimento e não trazer maiores dificuldades aos estudantes.
}

Já em relação ao computador, percebemos que o mesmo é uma plataforma acessível para a maioria dos estudantes, com exceção de um aluno que respondeu o questionário. Da mesma forma que a informação sobre acesso à internet e aparelhos celulares foi essencial para o planejamento das atividades que seriam realizadas na disciplina, o conhecimento de que quase $100 \%$ da turma possuía acesso a computadores nos permitiu usufruir com maior liberdade de ferramentas e recursos virtuais, novamente dando ênfase ao Moodle, que pode ser acessado tanto por celulares quanto por computadores e possibilita uma melhor organização da disciplina, com atividades previstas, materiais e meios de comunicação. Os estudantes que participaram da pesquisa utilizam o computador com muita frequência, principalmente como fonte de pesquisa, explicitado em uma resposta retirada do questionário:

"Computador uso na universidade para estudar, olho vídeo aulas, pesquiso assuntos. O celular uso quando não tenho como vir para o campus estudar, então faço minhas pesquisas nele, porém acho bem ruim usar o celular para estudar, porque tem muitas distrações." Resposta do aluno $\mathrm{A} 10$

Quando questionados sobre experiências associadas a uso de diferentes metodologias de ensino, poucos haviam tido experiências dentro da sala de aula. Aqueles que tiveram citaram as metodologias ativas "Just-in-Time Teaching", "Peer instruction" e simulações computacionais, que foram utilizadas em uma disciplina anterior à Física Geral I:

"Sim, tive contato com o Just-in-Time Teaching, com o Team Based Learning e com o Peer Instruction." Resposta do aluno B.

"Sim, apenas na sala de aula, em disciplina do semestre passado, via software Tracker e Modellus. O contato foi pouco, perdemos mais tempo tentando entender os comandos do programa do que fazendo as simulações, achei um pouco difícil de mexer nos softwares durante a aula, seria melhor ter algum tutorial para aprender a usar em casa e depois realizar as simulações em sala de aula, com ajuda do professor e monitores." Resposta do aluno $\mathrm{C}$.

Com essas informações, pudemos notar que apesar de alguns alunos possuírem experiências anteriores com o

\footnotetext{
10 Os nomes dos estudantes foram omitidos a fim de manter o sigilo sobre as suas identidades.
} 
Just-in-Time Teaching, para a maior parte da turma essa metodologia ativa era nova e surgia como um diferencial. Com base nessas informações, o desenvolvimento das atividades propostas tinha que levar em consideração que grande parte dos alunos nunca havia realizado tais tarefas e, portanto, as propostas deveriam ser explicadas de forma clara, assim como seus objetivos e modos de aplicação.

\section{Estratégias para Análise dos Dados}

A análise dos dados teve como foco investigar as potencialidades e o impacto do JiTT quando empregado no âmbito do Ensino Superior de Física. Em especial se essa metodologia, nesse contexto, desenvolvia um ritmo de estudos contínuo nos estudantes.

Para a análise das questões de caráter aberto (entendese aqui como questões dissertativas), nas quais os alunos podiam responder livremente sobre a temática envolvida, utilizamos como metodologia de análise de dados a Análise Textual Discursiva (ATD) descrita por Moraes e Galiazzi [22]. A ATD, de acordo com Moraes [23] e Moraes e Galiazzi [22, 24], caracteriza-se como "[...] uma abordagem de análise de dados que transita entre duas formas consagradas de análise de pesquisa qualitativa, que são a análise de conteúdo e análise de discurso" [22, p. 118]. Segundo Moraes, a Análise Textual Discursiva

"[...] pode ser compreendida como um processo autoorganizado de construção de compreensão em que novos entendimentos emergem de uma sequência recursiva de três componentes: desconstrução do corpus, a unitarização, o estabelecimento de relações entre os elementos unitários, a categorização, e o captar do novo emergente em que nova compreensão é comunicada e validada" [23, p. 192].

Uma das características da ATD em sua utilização como ferramenta de análise de dados qualitativos é o método de escolha de categorias e subcategorias em que as respostas podem ser encaixadas, sendo que "[...] as categorias emergem resultantes deste movimento de compreensão do que está sendo significado pelo pesquisador" [22, p. 125]. Essas categorias são, portanto, baseadas diretamente nos discursos encontrados nas respostas e a organização destas se faz através da correspondência de discursos semelhantes dentro de uma mesma questão. Sobre a ATD e o processo de categorização utilizado, Moraes e Galiazzi afirmam que

"Cada categoria representa um conceito dentro de uma rede de conceitos que pretende expressar novas compreensões. As categorias representam os nós de uma rede. $\mathrm{O}$ pesquisador ao tecer sua rede precisa preocupar-se especialmente com os nós, ou seja, os núcleos ou centros das categorias [...]. Por isso o processo de categorização precisa investir na definição e explicitação do núcleo das categorias emergentes, deixando que se estabeleçam entrelaçamentos na superposição das fronteiras, garantindo-se desta forma a constituição de um todo integrado" [22, p. $125]$
Uma vez definidas a metodologia e a ferramenta de análise de dados qualitativos, avançamos nesse momento para a análise dos resultados.

\section{Análise dos Resultados}

A análise da implementação da metodologia JiTT se deu tanto na forma qualitativa quanto quantitativa. Através da coleta de dados das realizações das tarefas foi possível determinar como se deu a variação da quantidade de alunos que faziam as TL e assim pudemos formular hipóteses sobre esse resultado. Além disso, um questionário final (como já mencionado anteriormente) foi aplicado e analisado, no qual propusemos questões avaliativas sobre a sequência na visão dos estudantes.

Através das respostas que foram submetidas às TL, pode-se construir um gráfico, o qual mostra a quantidade de alunos que realizaram cada uma delas (Figura 2). Na Tabela 3 da seção quatro é possível visualizar os temas de cada Tarefa de Leitura e os recursos utilizados.

Com base na Figura 2 é possível analisar a evolução da aplicação das TL ao longo do semestre. Uma das primeiras observações importantes é que o número de envios de respostas médio $(19,9)$ é alto quando comparado com a quantidade de alunos regularmente matriculados e que seguiram na disciplina até o final: de uma turma de 31 alunos matriculados (o número de alunos que de fato frequentaram a disciplina, desde o início, é 25), cerca 64,5\% mantiveram-se ativos em relação ao envio dessas tarefas e frequentando as aulas. Um segundo ponto que pode ser observado é o número aproximadamente constante de envios, ou seja, a quantidade de respostas submetidas em cada TL difere pouco da média citada anteriormente. Por fim, também fica claro na análise do gráfico acima que, apesar de não haver uma grande variação no número de respondentes em cada TL, é possível perceber que houve uma pequena redução do número de envios de respostas das TL ao longo do semestre.

Partindo desses pressupostos, algumas considerações mais específicas também podem ser feitas, como a Tarefa

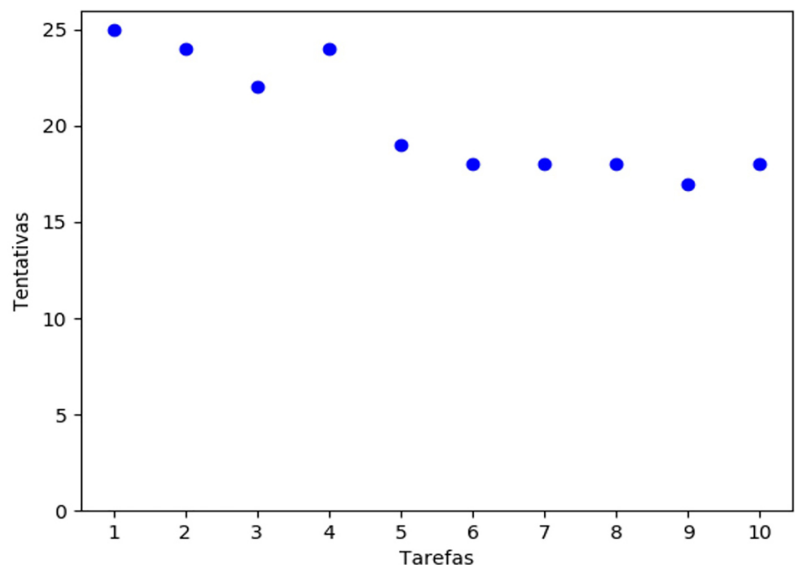

Figura 2: Quantidade de alunos respondentes em cada Tarefa de Leitura. 
de Leitura que mais recebeu envios e aquela com o menor número de respostas. Pode-se notar que a primeira TL aplicada foi a que recebeu o maior número de respostas e que a redução mais significativa dos envios ocorreu na TL 9. A partir dessas análises podemos especular sobre quais fatores levaram aos resultados da aplicação dessas Tarefas de Leitura que analisamos através do gráfico. Nesse sentido, acreditamos que podemos analisar o contexto e materiais utilizados nessas TL para concluirmos quais fatores podem ter influenciado esses resultados. A Tarefa de Leitura 1 - Medição e Grandezas - que foi a que recebeu maior número de envios, foi de fato a primeira das TL realizadas e também foi uma das mais elogiadas nos comentários elaborados pelos alunos por conter um elemento audiovisual (vídeo) com o qual eles se identificaram, além de afirmarem que o tema era extremamente interessante. Já a Tarefa de Leitura 9 - Colisões - em que o menor número de envios foi identificado, muitos alunos reclamaram da ferramenta utilizada - uma simulação do projeto PhET ${ }^{11}$ apesar de muitos citarem a atividade como esclarecedora para os conteúdos que iriam estudar.

Sobre a questão da redução do número de envios, notase que a queda mais significativa ocorreu nas últimas TL aplicadas, ou seja, no final do semestre. Podemos relacioná-la à grande carga de estudos e trabalhos que os alunos poderiam estar submetidos, já que a maioria também estava envolvida com outras disciplinas e atividades fora da sala de aula. Além disso, essa redução evidencia uma realidade que, apesar de já estar sendo combatida, ainda é bastante comum nos cursos de Bacharelado e Licenciatura em Física da Universidade Federal do Rio Grande do Sul a evasão. Segundo a literatura da área, o problema da evasão no Ensino Superior é especialmente relevante no primeiro ano de curso, dado que é neste período que ocorre a maior taxa de abandono $[25,26]$. Tendo isso em vista, conhecendo a realidade do Instituto de Física da Universidade Federal do Rio Grande do Sul no que diz respeito a esse panorama [27-29] e considerando que a disciplina discutida no presente artigo é ofertada para estudantes que estão, via de regra, no primeiro ou segundo semestre de curso, é compreensível

11 https://phet.colorado.edu/pt_BR/ que o número de alunos que enviaram as tarefas siga um padrão decrescente ao longo do semestre.

Quanto ao número de envios ser alto e constante ao longo do semestre, acreditamos que os alunos se comprometeram com a atividade proposta, aceitando a aplicação do JiTT através das TL, ou seja, eles adotaram a metodologia com significante responsabilidade e engajamento.

Para avaliar melhor a aplicação do Just-in-Time Teaching (e consequentemente das TL) na referida disciplina, aplicamos um questionário fina ${ }^{12}$ optativo, que não era identificado e tampouco avaliativo, o qual foi respondido por 11 alunos, e a partir dele fizemos a análise de algumas questões selecionadas (link para o questionárid ${ }^{13}$, a saber, as questões listadas abaixo, na Tabela 5 , da forma como enunciadas no formulárid 14

É interessante ressaltar, antes da análise de cada questão individualmente, que apesar de apenas 11 alunos terem respondido o questionário, entendemos que esse número é representativo na turma em que a metodologia foi aplicada. O que nos permite esse entendimento são alguns outros números da disciplina, alguns já destacados: 31 estudantes estavam matriculados, porém logo nas primeiras aulas, apenas 25 estavam comparecendo com frequência; além disso, ao final do semestre, 20 estudantes realizaram a última avaliação; destes, 13 foram aprovados e 7 necessitaram fazer o exame final; entretanto, dos 7 , apenas 5 realizaram essa última avaliação. Portanto, consideramos o quantitativo de 11 alunos que responderam o questionário é uma amostra representativa da turma, visto que o questionário era opcional e não avaliativo, e já esperávamos que os estudantes mais comprometidos com a disciplina o responderiam. Se entendermos que esse comprometimento se manifesta como a tentativa, até a última instância, de buscar a aprovação, então temos 11 respondentes em um universo de 18 estudantes, resultando em $61 \%$ do total.

\footnotetext{
$1 2 \longdiv { \mathrm { O } }$ questionário final foi validado por uma banca externa de três professores doutores.

13 https ://docs .google.com/forms/d/1xwqD5IVQNPutmMyFFiY2kIFeIdBTTqXkSjSkCDSJto/edit

14 Cabe destacar que não realizamos aqui a análise de todas as questões propostas no questionário por limitações de espaço e de relevância para a pesquisa.
}

Tabela 5: Questões selecionadas do questionário.

\begin{tabular}{|c|c|}
\hline Questão & Enunciado \\
\hline 1 & $\begin{array}{l}\text { Em uma escala de } 1 \text { a } 5 \text {, sendo } 1 \text { muita dificuldade e } 5 \text { nenhuma dificuldade, avalie como foi o seu desenvolvimento } \\
\text { das tarefa de leitura ao longo do semestre. }\end{array}$ \\
\hline 2 & $\begin{array}{l}\text { Em uma escala de } 1 \text { a } 5 \text {, sendo } 1 \text { pouco relevante e } 5 \text { muito relevante, avalie quanto o Just-in-Time Teaching foi } \\
\text { importante para um melhor aprendizado durante o semestre. }\end{array}$ \\
\hline 3 & $\begin{array}{l}\text { Em uma escala de } 1 \text { a } 5 \text {, sendo } 1 \text { ajudou muito pouco e } 5 \text { ajudou muito, avalie quanto o Just in Time Teaching } \\
\text { auxiliou o seu desempenho ao longo do semestre, na disciplina de Física Geral I - A. }\end{array}$ \\
\hline 4 & Você acha que os contextos utilizados nas Tarefas de Leitura foram relevantes para a reflexão dos conteúdos estudados? \\
\hline 5 & Você recomendaria que essa metodologia fosse implementada em outras disciplinas? \\
\hline 6 & A metodologia lhe ajudou a criar um hábito de estudo? \\
\hline 7 & $\begin{array}{l}\text { Você utilizou o hábito de estudo criado a partir da experiência com o Just-in-Time Teaching para estudar outras } \\
\text { disciplinas? }\end{array}$ \\
\hline 8 & Cite alguma(s) vantagem(ns) que você tenha identificado em utilizar o Just-in-Time Teaching. \\
\hline 9 & Cite alguma(s) desvantagem(ns) que você tenha identificado em utilizar o Just in Time Teaching. \\
\hline
\end{tabular}


Abaixo, na ordem apresentada, passamos a analisar cada uma das questões colocadas na Tabela 5 .

Questão 1 - Utilizando uma escala Likert de 5 pontos (recurso que será adotado também em questões posteriores), os alunos foram questionados sobre o desenvolvimento das Tarefas de Leitura ao longo do semestre, em termos de níveis de dificuldade ou facilidade na realização destas (a escala variava de 1 a 5 , sendo 1 muita dificuldade e 5 nenhuma dificuldade). A maior parte dos alunos $(72,7 \%)$ respondeu que teve certa facilidade, enquanto que $27,3 \%$ apontaram um nível médio de dificuldade.

Esse resultado indica que as atividades desenvolvidas não tiveram um nível de complexidade alto e foram acessíveis aos alunos, condição fundamental quando pensamos que elas devem ser realizadas antes da aula, ainda sem contato formal com o conteúdo.

Questão 2 - Quando questionados sobre a importância da aplicação das Tarefas de Leitura para o aprendizado dos conceitos físicos durante o semestre, foi solicitado que o aluno classificasse de 1 a 5 a relevância identificada (sendo 1 pouco relevante e 5 muito relevante). A partir das respostas, percebemos que, na opinião dos participantes, as TL estiveram positivamente relacionadas com o aprendizado, afinal, em 36,4\% dos alunos classificaram as TL como muito relevantes para o aprendizado, outros $36,4 \%$ classificaram como relevante (observemos que quase $73 \%$ dos participantes optaram por avaliações positivas) e $27,2 \%$ dos alunos apontaram relevância média para a aplicação.

Questão 3 - Perguntados sobre o quanto o Just-inTime Teaching auxiliou o seu desempenho ao longo do semestre, na disciplina de Física Geral I, utilizando uma escala Likert de 1 a 5 (sendo 1 ajudou muito pouco e 5 ajudou muito), 45,5\% responderam que auxiliou muito, $18,2 \%$ responderam que a ajuda foi relevante e $36,3 \%$ responderam que a ajuda foi mediana. Podemos perceber, através dessas respostas, que todos os alunos acreditam que as Tarefas de Leitura influenciaram, mesmo que de maneira não tão expressiva, em seus desempenhos no semestre.

Para melhor visualização e compreensão dos resultados das questões objetivas, a Tabela 6 , abaixo, mostra os gráficos gerados através das respostas - com opções de sim, não ou talvez - submetidas pelos alunos para cada uma das questões apresentadas. Nessas questões, tentamos avaliar a capacidade de o JiTT proporcionar um ritmo de estudos para cada estudante.

A Tabela 6 abaixo destacada traz importantes resultados acerca da questão de desenvolvimento de um ritmo de estudos. Na primeira perguntas, quando questionamos sobre a contextualização das TL, $81,8 \%$ acreditam que este é um fator relevante para a disciplina. Esse aspecto endossa mais uma vez a importância percebida pelos estudantes da estrutura planejada e desenvolvida.

Munidos do resultado anteriormente destacado, ainda analisando a Tabela 6 , questionamos se a utilização dessa metodologia deveria ser ampliada a outras disciplinas curriculares. Essa informação busca equalizar a carga de trabalho gerada pela metodologia aqui empregada, com as vantagens que a mesma traz no desenvolvimento do acadêmico. O resultado, como percebemos no segundo gráfico, indica que aproximadamente $63 \%$ dos participantes que responderam o questionário final afirmam recomendar a utilização do JiTT em outras disciplinas, o que na visão dos pesquisadores pode estar relacionado com a boa avaliação do método. Percebemos que apenas 9,1\% (um participante) não recomendaria, o que também é compreensível, uma vez que a carga de trabalho pré-classe se acentua quando dispomos de estruturas que utilizam o JiTT, tal resultado já era esperado e serve para corroborar com o previsto por Oliveira, Veit e Araujo [15].

A imagem da questão 6 na Tabela 6 traz um resultado essencial, já que um dos principais objetivos do JiTT era promover um hábito de estudo, incentivando-os com as Tarefas de Leitura propostas. Questionados, então,

Tabela 6: Relação gráfica das respostas objetivas.

\begin{tabular}{|c|c|c|c|}
\hline $\begin{array}{l}\text { Questão } 4 \text { - Você acha que os } \\
\text { contextos utilizados nas Tare- } \\
\text { fas de Leitura foram relevantes } \\
\text { para a reflexão dos conteúdos } \\
\text { estudados? }\end{array}$ & $\begin{array}{l}\text { Questão } 5 \text { - Você recomenda- } \\
\text { ria que essa metodologia fosse } \\
\text { implementada em outras disci- } \\
\text { plinas? }\end{array}$ & $\begin{array}{l}\text { Questão } 6 \text { - A metodologia lhe } \\
\text { ajudou a criar um hábito de } \\
\text { estudo? }\end{array}$ & $\begin{array}{l}\text { Questão } 7 \text { - Você utilizou o há- } \\
\text { bito de estudo criado a partir } \\
\text { da experiência com o Just-in- } \\
\text { Time Teaching para estudar } \\
\text { outras disciplinas? }\end{array}$ \\
\hline
\end{tabular}
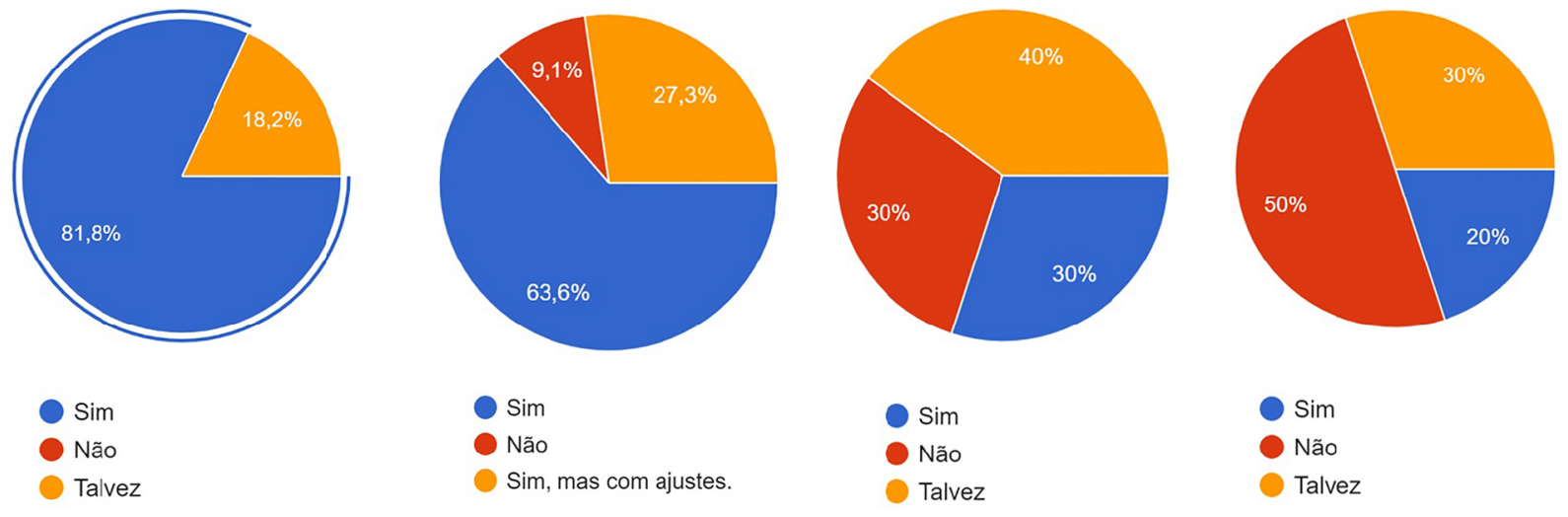
sobre se a metodologia teria ajudado a criar um hábito de estudos, $30 \%$ do total de alunos que responderam ao questionário marcaram que "sim" e outros $30 \%$ afirmaram que "não". O restante da amostra (40\%) preferiu responder com "talvez", o que pode indicar dúvidas dos alunos quanto ao que pode ser considerado como hábito de estudo. Esse resultado mostra que os alunos ficaram divididos sobre as influências do JiTT na questão dos estudos individuais, porém, apresenta um bom resultado quanto àqueles que identificaram uma modificação do hábito de estudos com a aplicação da metodologia, que vai ao encontro de apontamentos de Guertin, Zappe e Kim [11], corroborando com os resultados esperados da aplicação.

Finalizando a análise das questões objetivas, o gráfico da questão 7 mostrado na Tabela 6 acima apresenta uma contradição de respostas quando comparado ao gráfico gerado a partir da questão 5 da mesma tabela. Enquanto na questão de recomendação a maioria dos alunos respondeu que indicaria a implementação da metodologia em outras disciplinas, quando perguntados se o hábito de estudos criado através do JiTT auxiliou para os estudos de outras disciplinas, $50 \%$ responderam que não e somente $20 \%$ afirmaram que sim. Essa diferença pode ter ocorrido pelo fato de que nem todos os alunos identificaram a influência da aplicação da metodologia em suas rotinas de estudos e, por isso, não poderiam realizá-la também em outras disciplinas.

Uma vez finalizada a análise das questões objetivas, passamos agora às questões dissertativas propostas no questionário e que versam sobre as vantagens e as desvantagens da utilização do JiTT.

Como metodologia analítica das informações, conforme já destacamos em seção anterior, utilizamos a Análise Textual Discursiva (ATD) descrita por Moraes e Galiazzi [22]. Assim, fazendo uso desse recurso de análise de dados, passamos para a análise das duas questões dissertativas propostas aos estudantes no questionário final.

Questão 8 - Quando questionados sobre as vantagens da aplicação das Tarefas de Leitura como ferramenta da metodologia ativa de ensino (JiTT), os alunos citaram alguns fatores importantes a serem observados e que podemos agrupar em três categorias definidas e caracterizadas abaixo (após cada categoria são colocados trechos de respostas dos estudantes, exemplificando-as):

1. Estudo antes das aulas: $63,6 \%$ das respostas mencionaram o estudo antes das aulas, proporcionado pela realização das tarefas e como isso os preparava para os conteúdos que seriam abordados em sala. Dentro desta categoria surgiram duas subcategorias, descritas a seguir:

1.1 Introdução dos conteúdos: muitas respostas citaram que as TL apresentavam como vantagem uma prévia dos assuntos que seriam vistos em aula e que era importante para esclarecer alguns conceitos básicos [10].

1.2 Formas diferentes de estudo e pesquisa: os alunos descreveram que ao realizarem as Tarefas de Leitura eles precisavam, muitas vezes, buscar por informações através de fontes de pesquisa e, até mesmo, usavam outras ferramentas de estudo [15].

As respostas abaixo podem justificar essa categoria e suas subcategorias:

"A noção básica a ser estudada sobre o assunto antes de estar em sala de aula." Resposta do aluno C.

"Você pode ter uma prévia do que vai estudar, mesmo antes do professor passar em aula. Isso gera uma boa ajuda, ou seja, facilita o entendimento em aula." Resposta do aluno D.

"Dependendo do conteúdo, você tem que recorrer para outros métodos de pesquisa o que vai ajudar a te aprofundar no assunto." Resposta do aluno B.

2. Associação dos conteúdos com a realidade: as respostas mostraram que os temas utilizados nas Tarefas de Leitura eram muito convenientes para mostrar as aplicações dos conceitos da Física no cotidiano, de forma semelhante isto é visto na aplicação de Guertin, Zappe e $\operatorname{Kim}[11]$.

As respostas abaixo evidenciam essa categoria:

"Associar os assuntos estudados com a realidade, com temas mais práticos." Resposta do aluno G.

"Esclarecer alguns conceitos e associar os conteúdos a atividades comuns." Resposta do aluno F.

3. Trabalho do professor: houve ainda quem tenha observado que as TL auxiliavam no trabalho do professor de preparar e organizar as aulas baseado nas respostas e dúvidas dos alunos em relação às tarefas.

A resposta que pode justificar essa categoria é a que segue:

"[...] permite ao professor conhecer o nível de conhecimento da classe, evitando dar aulas sobre conteúdos que os alunos já sabem, priorizando aqueles que os alunos mais erram/desconhecem." Resposta do aluno D.

Questão 9 - Sobre as desvantagens da aplicação das Tarefas de Leitura, a maioria dos alunos respondeu a questão falando de problemas ou dificuldades que encontrou na realização destas e não as desvantagens da aplicação em si. Ainda assim, podemos dividir as respostas submetidas nas seguintes categorias:

1. Dificuldades na realização das tarefas: $36,4 \%$ das respostas apresentaram algum tipo de crítica às TL, relacionadas a alguma ferramenta ou material utilizado e que geraram certa dificuldade de acesso ou realização da tarefa. Essa categoria pode ser subdividida nos itens abaixo:

1.1 Falta de tempo: esse item aparece de duas formas dentro desta subcategoria, pois alguns alunos citaram que o tempo de realização de algumas tarefas, em si, era curto, e outros falaram que o período de tempo em que as tarefas ficavam disponíveis também era pequeno.

1.2 Manipulação da plataforma e/ou ferramentas de acesso: as respostas mencionaram algumas dificuldades encontradas no manuseio das ferramentas de estudo propostas em determinadas tarefas e também do acesso a alguns materiais, assim como adversidades relacionadas ao uso da plataforma Moodle. 
As respostas abaixo descrevem as desvantagens citadas pelos alunos:

"[...] Por ser muito em cima o tempo para fazer as tarefas, em época de prova alguma pode passar esquecida." Resposta do aluno E.

"[...] às vezes não conseguia ter acesso a um computador e a simulação não abria direito [...]." Resposta do aluno A.

Cabe destacar aqui algumas considerações relacionadas a argumentação do tempo, exposta pelos estudantes em uma das categorias. O tempo para realização da atividade, de fato era curto. O prazo não excedia dois dias. Esse aspecto considera o curto período de tempo para realização da TL e também a necessidade do professor se inteirar das respostas e análises para o desenvolvimento da aula subsequente. Como já destacamos, as atividades eram curtas, de tempo médio de execução inferior a trinta minutos, logo, o prazo de execução nos parecia perfeitamente exequível. De qualquer forma, é um aspecto que necessita ser confrontado em futura aplicação e desenvolvimento.

\section{Considerações Finais}

Neste trabalho vimos que as metodologias ativas podem ser uma alternativa ao ensino tradicional, principalmente ao Ensino de Física que se mostra defasado nos últimos tempos. Essas metodologias, de modo geral, têm como objetivo aproximar teoria e prática através de processos interativos de conhecimento, pesquisa e análise de forma individual ou coletiva. Com base neste princípio, elegemos o Just-in-Time Teaching, uma metodologia que utiliza momentos pré-classe para preparar o aluno sobre o tema que será trabalhado e assim otimizando o tempo de aula e ainda afirma desenvolver os hábitos de estudos desses estudantes.

Para melhor entender como o JiTT vem sendo trabalhado, utilizamos como base o método desenvolvido por Novak et al. [9] e realizamos uma revisão sistemática da literatura, passando por revistas de nível A1, A2 e B1 do qualis Capes, e assim foram encontrados sete artigos que foram analisados. Nestes artigos, buscamos principalmente aqueles que tratavam de aplicações para que pudéssemos analisar os resultados obtidos e as alterações realizadas no método original de Novak et al. [9], assim, restaram apenas quatro para análise. Todos os artigos encontrados mostraram resultados positivos.

Com a análise dos artigos em mãos, foi montada uma sequência de tarefas que visa a contextualização dos conteúdos de uma disciplina inicial de mecânica em um curso de Física. Foram realizadas dez tarefas com base nos principais conceitos trabalhados na disciplina e nos livros textos sugeridos.

Para avaliar os resultados do JiTT, utilizamos a ATD e analisamos dados sobre a quantidade de alunos que realizaram cada tarefa, nos permitindo uma visão quantitativa sobre a participação dos estudantes. Ainda, em cada tarefa foi disponibilizado um espaço para que os alunos pudessem apontar suas dificuldades, facilidades e opiniões (se foi útil, fácil, ocupou muito tempo ou semelhantes). Este tipo de questão nos permitiu tirar conclusões qualitativas sobre o método em si e trazer apontamentos sobre as dificuldades das questões.

Após analisar os resultados, percebemos que o método é promissor no quesito contextualização e aceitação. Apenas um dos alunos não recomendaria o método, o que é compreensível considerando o aumento da dedicação necessária para a disciplina. Sobre a aceitação do método, foram diversos comentários em prol da aplicação, dado que os alunos perceberam a importância de estudar o tema antes de ser visto em sala de aula, perceberam que as tarefas auxiliaram o professor no preparo da aula e houve apontamentos, por parte dos alunos, sobre situações cotidianas que conseguiram visualizar ao realizarem as tarefas.

Considerando a questão de pesquisa colocada inicialmente, como mostrado nos resultados, os alunos apresentaram dúvidas quanto ao que seria considerado como hábito de estudos, porém, de acordo com as respostas e relatos apresentados no questionário, pudemos identificar significativas mudanças em suas concepções de estudos, na contextualização dos conteúdos e na forma como veem os estudos pré-classe, o que identificamos como uma progressão da visão do aluno quanto ao estudo fora da sala de aula, o que auxilia no desenvolvimento e no reconhecimento de uma rotina de estudos individual como uma sucessão de ações que podem ser realizadas de diferentes formas por cada estudante.

\section{Referências}

[1] A.S. Vieira, Uma alternativa didática às aulas tradicionais: o engajamento interativo obtido por meio do uso do método Peer Instruction (Instrução pelos colegas). Dissertação de Mestrado, Universidade Federal do Rio Grande do Sul, Porto Alegre (2014).

[2] E.C. Ricardo, em: Ensino de Física (Coleção Ideias em Ação), editado por A.M.P. de Carvalho (Cengage Learning, São Paulo, 2010).

[3] F.F.D. Oliveira, D.M. Vianna e R.S. Gerbassi, Revista Brasileira de Ensino de Física 29, 447 (2007).

[4] N.A.N. Berbel, Semina: Ciências Sociais e Humanas 32, 25 (2011).

[5] G.S. Selçuk, International Journal of the Physical Sciences 5, 711 (2010).

[6] W.N. Bender, Aprendizagem Baseada em Projetos: educação diferenciada para o século XXI (Penso, Porto Alegre, 2014).

[7] R. Donnelly e M. Fitzmaurice, em: Emerging Issues in the Practice of University Learning and Teaching, editado por G. O'Neill, S. Moore e B. McMullin (AISHE, Dublin, 2005).

[8] E. Mazur, Peer Instruction: A User's Manual (Prentice Hall, New Jersey, 1997).

[9] G.M. Novak, E.T. Patterson, A.D. Gavrin e W. Christian, Just-in-Time Teaching: blending active learning with web technology (Prentice Hall, Upper Saddle River, 1999). 
[10] I.S. Araujo e E. Mazur, Caderno Brasileiro de Ensino de Física 30, 362 (2013).

[11] A.L. Guertin, S.E. Zappe e H. Kim, Journal of Science Education and Technology 16, 507 (2007).

[12] N. Lasry, M. Dugdale e E. Charles, The Physics Teacher 52, 34 (2014).

[13] D. MacIsaac, The Physics Teacher 43, 398 (2005).

[14] H.E. Mohottala, The Physics Teacher 51, 44 (2013).

[15] V. Oliveira, E.A. Veit e I.S. Araujo, Caderno Brasileiro de Ensino de Física 32, 180 (2015).

[16] T. Espinosa, I.S. Araujo e E.A. Veit, Revista de Enseñanza de la Física 30, 59 (2018).

[17] J. Elliott, Journal of Curriculum Studies 10, 355 (1978).

[18] W. Carr e S. Kemmis, Becoming Critical: education, knowledge and action research (Falmer Press, Brighton, 1986).

[19] D. Auler e D. Delizoicov, Revista Ensaio - Pesquisa em Educação em Ciências 3, 122 (2001).

[20] D.S. Kato, O significado pedagógico da contextualização para o ensino de ciências: análise dos documentos curriculares oficiais e de professores. Dissertação de Mestrado, Universidade de São Paulo, São Paulo (2007).

[21] E.C. Ricardo, Competências, Interdisciplinaridade e Contextualização: dos Parâmetros Curriculares a uma compreensão para o ensino das ciências. Tese de Doutorado, Universidade Federal de Santa Catarina, Florianópolis (2005).

[22] R. Moraes e M.C. Galiazzi, Ciência \& Educação 12, 117 (2006).

[23] R. Moraes, Ciência \& Educação 9, 191 (2003).

[24] R. Moraes e M.C. Galiazzi, Análise Textual Discursiva (Editora Unijuí, Ijuí, 2011).

[25] M.M. Braga, M.C. Peixoto e T.F. Bogutchi, Avaliação: Revista da Avaliação da Educação Superior 8, 161 (2003).

[26] R.L.L. Silva Filho, P.R. Motejunas, O. Hipólito e M.B.C.M. Lobo, Cadernos de pesquisa 37, 641 (2007).

[27] L.T. Pigosso, B.S. Ribeiro e L.A. Heidemann, Revista Brasileira de Pesquisa em Educação em Ciências 20, 245 (2020).

[28] L.A. Heidemann, K.R.M. Moraes e S.L. Giongo, Revista Brasileira de Ensino de Ciências e Matemática 3, 160 (2020).

[29] K.R.M. Moraes, Uma investigação exploratória sobre as implicações das experiências de primeiro semestre de curso na decisão de evadir ou persistir dos estudantes de licenciatura em física da UFRGS. Dissertação de Mestrado, Universidade Federal do Rio Grande do Sul, Porto Alegre (2020). 